\title{
Ecotropic viral integration site 1 regulates the progression of acute myeloid leukemia via MS4A3-mediated TGF//EMT signaling pathway
}

\author{
MIN JIANG ${ }^{1,2}$, XUEQIN ZOU ${ }^{3}$ and WENHUA HUANG ${ }^{1}$ \\ ${ }^{1}$ Department of Anatomy, School of Basic Medical Sciences, Southern Medical University, Guangzhou, Guangdong 510515; \\ ${ }^{2}$ Department of Pediatrics, The Fifth Hospital of Xiamen, Affiliated TongMin Hospital of Xiamen University, \\ Xiamen, Fujian 361101; ${ }^{3}$ Department of Internal Medicine, The First College of Clinical Medical Science, \\ China Three Gorges University, Yichang Central People's Hospital, Yichang, Hubei 443003, P.R. China
}

Received May 8, 2017; Accepted December 19, 2017

DOI: $10.3892 / \mathrm{ol} .2018 .8890$

\begin{abstract}
Acute myeloid leukemia (AML) is a type of malignant tumor that is caused by malignant clone hematopoietic stem cells. The ecotropic viral integration site 1 (Evi1) is a zinc finger transcription factor, which is highly expressed in AML, and its expression level has been associated with poor prognosis of AML. Previous studies have indicated that Evi1 may regulate cell proliferation, differentiation and apoptosis by inhibiting the membrane-spanning-4-domains subfamily-A member-3 (MS4A3) gene in AML. The aim of the present study was to investigate the role of Evil in the progression of AML. The results revealed that Evil was overexpressed in leukemia cells compared with normal $\mathrm{T}$ lymphocytes. MicroRNAs (miR)-133 and -431 that target Evil were investigated, and it was observed that there was a low expression of miR-431 in AML. The transfection of miR-431 was able to decrease the promoter methylation levels of the Evil gene in AML cells. The transfection of miR-431 also suppressed the migration and invasion of AML cells. The present study revealed that the transfection of miR-431 mimic was able to downregulate MS4A3 expression in AML cells. Furthermore, the expression levels of transforming growth factor $\beta$ (TGF $\beta$ ) and epithelial-to-mesenchymal transition (EMT) markers fibronectin, $\alpha$-smooth muscle actin, and vimentin were downregulated following the transfection of miR-431 in AML cells. The overexpression of MS4A3 was also able to suppress
\end{abstract}

Correspondence to: Professor Wenhua Huang, Department of Anatomy, School of Basic Medical Sciences, Southern Medical University, 1838 Guangzhou Road North, Guangzhou, Guangdong 510515, P.R. China

Email: huangwenhuadoc@126.com

Key words: acute myeloid leukemia, ecotropic viral integration site 1, microRNA-431, membrane-spanning-4-domains subfamily-A member-3, transforming growth factor $\beta$, epithelial-to-mesenchymal transition
miR-431-mediated inhibition of the expression of TGF $\beta$ and EMT markers in AML cells. The addition of TGF $\beta$ inhibited the downregulation of EMT markers by transfection of miR-431 in AML cells. The transfection of miR-431 suppressed the migration and invasion of AML cells, which was also abolished by the addition of TGF $\beta$. In conclusion, the results of the present study indicated that Evil may be a potential molecular target of leukemia therapy via MS4A3-mediated TGF $\beta /$ EMT signaling pathway.

\section{Introduction}

Acute myeloid leukemia (AML) is a type of bone marrow leukocyte (white leukocyte) caused by abnormal proliferation of leukemia (1). AML is characterized by the rapid proliferation of abnormal cells in the bone marrow that affects the generation of normal blood cells (2). Clinical analyses indicate that AML may be induced by a variety of factors, including virus, ionizing radiation, chemical substances and genetic factors $(3,4)$. Fever, infirmity and other complications are the characteristics of patients with AML (4). A previous study analyzed therapy and efficacy post-remission of AML (5). Mechanism analyses have suggested that cellular molecular signaling pathways are involved in the progression of AML in patients $(6,7)$. Therefore, understanding the potential mechanisms of AML is essential for the development of therapy for AML.

The ecotropic viral integration site 1 (Evil) is a zinc finger transcription factor, which is highly expressed in numerous human tumors $(8,9)$. A report indicated that the overexpression of the EVI1 oncogene is associated typically with aggressive myeloid leukemia (10). Jazaeri et al (11) reported that Evi1 and EVI1s (Delta324) may be regarded as potential therapeutic targets in ovarian cancer. In addition, the transcription factor Evi1 may regulate cellular proliferation, differentiation and apoptosis, and its overexpression may contribute to an aggressive course of disease via transcriptional repression of membrane-spanning-4-domains subfamily-A member-3 (MS4A3) in AML and other malignancies (12). Furthermore, the results indicated that Evil is a transcriptional suppressor of 
the microRNA (miRNA)-143 gene, and miRNA-143 mediates its action via the K-Ras axis in human colon cancer (13). Additionally, Evi1 targets DeltaNp63 and upregulates the cyclin-dependent kinase inhibitor p21, independent of p53, which may delay cell cycle progression and cell proliferation in colon cancer cells (14). However, the potential underlying mechanism mediated by Evil in AML requires further investigation.

In the present study, Evi1 as a target of miR-431 was analyzed and a low expression of miR-431 was detected in AML cells. It was previously reported by the present authors that Evil is a potential molecular target for leukemia therapy via the TGF $\beta$-induced EMT signaling pathway. Therefore, the present study focused on the molecular mechanism of AML regulation by Evil via miR-431, which further mediate the TGF $\beta$-induced EMT signaling pathway in leukemia. It was indicated that miR-431 may suppress the invasion and proliferation of AML cells via the Evil-mediated MS4A3/TGFß/EMT signaling pathway.

\section{Materials and methods}

Cell culture. HuT-78, HTL-90 (http://www.cnki.com .cn/Article/CJFDTotal-HNLG6S1.025.htm) and normal T lymphocyte cells (15) were obtained from Department of Anatomy, Southern Medical University (Guangzhou, China) and cultured in Dulbecco's modified Eagle's medium (DMEM; Thermo Fisher Scientific, Inc., Waltham, MA, USA) with $5 \mu \mathrm{g} / \mathrm{m}$ blasticidin and supplemented with $10 \%$ fetal bovine serum (FBS, Thermo Fisher Scientific, Inc., Waltham, MA, USA). All cells were cultured in a $37^{\circ} \mathrm{C}$ humidified atmosphere of $5 \% \mathrm{CO}_{2}$.

Cell proliferation assay. All miR-431 mimics were synthesized by Invitrogen (Thermo Fisher Scientific, Inc.), including pmiR-431 pvector (control). The proliferation of pvector or pmiR-431-transfected HuT-78 cells was detected using Cell Counting Kit-8 (CCK-8) kit according to the manufacturer's protocols. Briefly, HuT-78 cells were cultured in 48-well plates at the density of $1 \times 10^{4}$ cells/well and then cultured for $24 \mathrm{~h}$. Finally, $10 \mu \mathrm{l}$ CCK-8 solution was added to each well and incubated for $2 \mathrm{~h}$ at $37^{\circ} \mathrm{C}$. The results were measured using a microplate reader (Bio-Rad Laboratories, Inc., Hercules, CA, USA) at $570 \mathrm{~nm}$.

Methylation assay. gDNA was extracted using phenolchloroform. A total of $2 \mu \mathrm{g}$ DNA in HuT-78 cells was treated with bisulfite using the EpiTect Bisulfite kit (Qiagen, Inc., Valencia, CA, USA), and polymerase chain reaction (PCR) was performed using PCR cloning kit (Zero Blunt ${ }^{\mathrm{TM}}$ PCR Cloning Kit, Invitrogen ${ }^{\mathrm{TM}}$; Thermo Sisher Scientific, Inc.) according to the manufacturer's protocol. Primer sequences were as follows: Forwards, 5'-AGGTTTTAGAGTAGGATT GGAAATGT-3' and reverse, 5'-ACCCCCTCTCCCAAAACT A-3'. The PCR conditions were set as following: An initial denaturation at $95^{\circ} \mathrm{C}$ for $60 \mathrm{sec}$, followed by 45 cycles of $95^{\circ} \mathrm{C}$ for $15 \mathrm{sec}, 58.5^{\circ} \mathrm{C}$ for $60 \mathrm{sec}, 72^{\circ} \mathrm{C}$ for $1 \mathrm{~min}$. Pyrosequencing was conducted according to the manufacturer's protocols of the PyroMark PCR kit (Qiagen, Inc.).

Reverse transcription-quantitative $(R T-q) P C R$. HuT-78, HTL-90 and normal T lymphocyte cells were cultured, and total RNA was isolated from HuT-78, HTL-90 and normal T lymphocytes using TRIzol reagent (Life Technologies; Thermo Fisher Scientific, Inc.) and transcribed into cDNA using Super Script VILO cDNA Synthesis kit (Life Technologies; Thermo Fisher Scientific, Inc.). The forward and reverse primers were synthesized by Invitrogen (Thermo Fisher Scientific, Inc.). The sequences of the primers were as follows: Evil forward, 5'-CACGGATCCGAGGCGCCATGTCAG AAC-3' and reverse, 5'-CTGACTCGAGGGATTAGGGCT TCCTCTTGG-3'; $\beta$-actin forward, 5'-CGGAGTCAACGG ATTTGGTC-3' and reverse, 5'-AGCCTTCTCCATGGTCGT GA-3'. The changes in relative mRNA expression were calculated using the $2^{-\Delta \Delta \mathrm{Cq}}$ method (16). The qPCR thermocycling conditions were as follows: $95^{\circ} \mathrm{C}$ for $5 \mathrm{~min}$, then 35 cycles of $95^{\circ} \mathrm{C}$ for $20 \mathrm{sec}, 56^{\circ} \mathrm{C}$ for $20 \mathrm{sec}$ and $72^{\circ} \mathrm{C}$ for $20 \mathrm{sec}$, and a final extension at $72^{\circ} \mathrm{C}$ for $5 \mathrm{~min}$. The results were expressed as the $\mathrm{n}$-fold way compared with the housekeeping gene ( $\beta$-actin).

Boyden chamber migration and invasion assays. Serum-free HuT-78 cells were seeded $\left(1 \times 10^{5}\right.$ cells/well) in $500 \mu$ I DMEM medium. For the invasion assay, HuT-78 cells were suspended at a density of $1 \times 10^{5}$ in $500 \mu \mathrm{l}$ serum-free DMEM. The cells were seeded in the upper Matrigel invasion chamber (BD Biosciences, Franklin Lakes, NY, USA) according to the manufacturer's protocols. For the migration assay, the cells were subjected to a control insert (BD Biosciences) instead of a Matrigel invasion chamber. The number of tumor cells that migrated and invaded was counted in $\geq 3$ randomly stained fields for every membrane under a light microscope at $\mathrm{x} 40$ magnification.

Transfection of miR-431. HuT-78 cells $\left(1 \times 10^{6}\right)$ were transfected with 100 pmol pmiR-431 (Applied Biosystems; Thermo Fisher Scientific, Inc.) with pvector as control (Applied Biosystems; Thermo Fisher Scientific, Inc.) by using a Cell Line Nucleofector kit L (Lonza Group, Ltd., Basel, Switzerland). After 72 h transfection, cells were used for further experiments. HuT-78 cells transfected with miR-431 and then were treated by TGF $\beta$ $(2 \mathrm{mg} / \mathrm{ml})$ for $12 \mathrm{~h}$ at $37^{\circ} \mathrm{C}$ for further analysis.

Construction of lentivirus for MS4A3 overexpression. S4A3 was cloned into a lentivirus plasmid using the Lentivirus vector system (System Biosciences, LLC, Pallo Alto, CA, USA) with vector as control. Plasmids were named pMS4A3 and pvector (control), respectively. All DNA sequences were synthesized by Invitrogen (Thermo Fisher Scientific, Inc.). pvector or pMS4A3 plasmid was transfected into HuT-78 cells using Lipofectamine ${ }^{\circledR} 2000$ (Invitrogen; Thermo Fisher Scientific, Inc.). The cells that were transfected with pvector or pMS4A3 were used for further analysis.

Western blotting. HuT-78 cells were collected and lysed in radioimmunoprecipitation assay buffer (M-PER reagent for the cells and T-PER reagent for the tissues, Thermo Fisher Scientific, Inc.) followed by homogenization at $4^{\circ} \mathrm{C}$ for $10 \mathrm{~min}$. Protein concentration was measured by a BCA protein assay kit (Thermo Scientific, Inc.). A total of $(20 \mu \mathrm{g})$ protein was electrophoresed on $12.5 \%$ polyacrylamide gradient gels and then transferred to nitrocellulose membranes. Rabbit anti-human antibodies used in the immunoblotting assays were: Evi1 
A

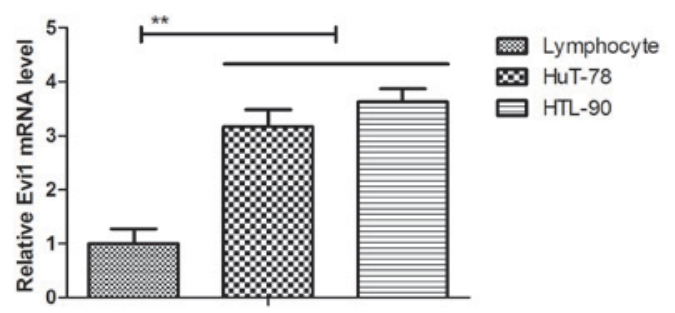

C

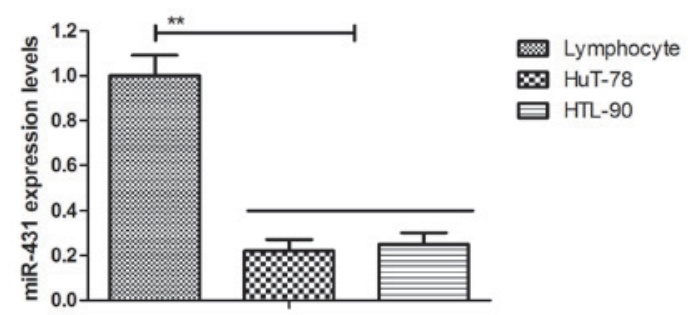

B

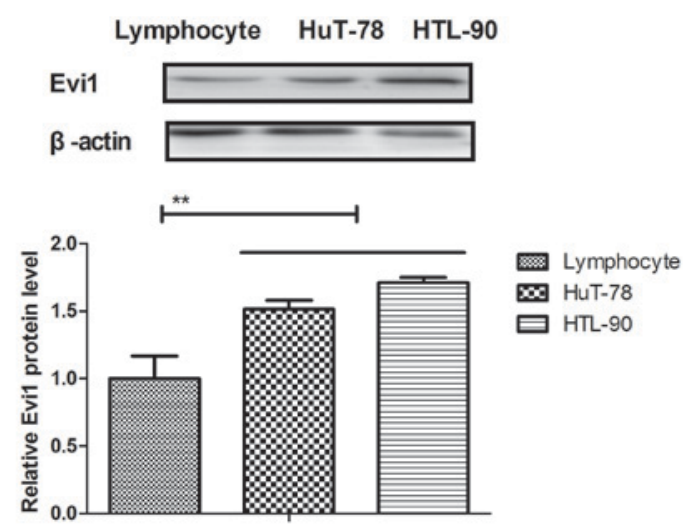

D

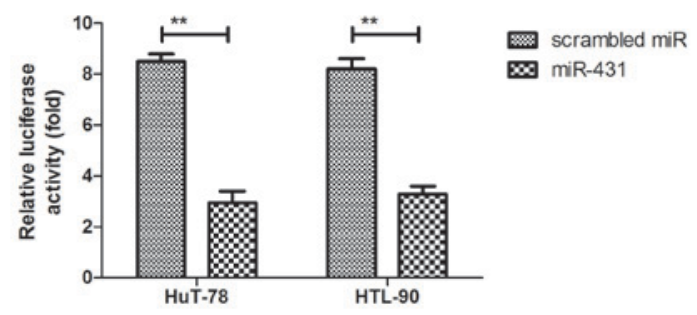

Figure 1. Analysis of Evi1 and miR-431 expression in acute myeloid leukemia cells. (A) mRNA and (B) protein expression levels of Evi1 were upregulated in HuT-78 and HTL-90 compared with normal T lymphocytes. (C) miR-431 expression levels were downregulated in HuT-78 and HTL-90 cells compared with normal T lymphocytes. (D) Evi1 is the target gene of miR-431 in HuT-78 and HTL-90 as determined by dual-luciferase reporter assay with scrambled miR as control. ${ }^{* *} \mathrm{P}<0.01$. Evi1, ecotropic viral integration site $1 ;$ miR, microRNA.

(1:500; catalog no. ab28457; Abcam, Cambridge, UK), MS4A3 (1:500; catalog no. ab173761; Abcam), TGF $\beta$ (1:200; catalog no. ab92486; Abcam), fibronectin (FIB; 1:500; catalog no. ab6328; Abcam), $\alpha$-smooth muscle actin ( $\alpha$-SMA; 1:500; catalog no. ab7817; Abcam), vimentin (VIM; 1:500; catalog no. ab92547; Abcam) and $\beta$-actin (1:500; catalog no. ab8226; Abcam). Horseradish peroxidase-conjugated anti-rabbit immunoglobulin G antibodies (cat. no. 166-2408-MSDS, Bio-Rad Laboratories, Inc.) were used at a 1:5,000 dilution and detected using a Western Blotting Luminol reagent (Roche Diagnostics, Basel, Switzerland). Densitometric quantification of the protein expression was performed using Quantity-One software (version 1.02; Bio-Rad Laboratories, Inc.).

Luciferase reporter assay. Evi1 3'untranslated region (UTR) construct in a PIS2 vector (Invitrogen; Thermo Fisher Scientific, Inc.) was used for luciferase reporter assay as described previously (17). Site-directed mutagenesis of the miR-431 binding site in Evil 3'UTR was analyzed using PCR amplification with the construction of a mutated 3'-UTR as control. HuT-78 and HTL-90 cells were transfected with Evi1 3'UTR (cytomegalovirus-driven $\beta$-gal reporter system, BD Biosciences) and miR-431 mimics or scrambled miR control using Lipofectamine ${ }^{\circledR} 2000$ (Invitrogen; Thermo Fisher Scientific, Inc.) for $24 \mathrm{~h}$ at $37^{\circ} \mathrm{C}$ with untransfected cells as controls. The cell pellets were analyzed using the luciferase reporter assay according to the manufacturer's protocols (Promega Corporation, Madison, WI, USA). The $\beta$-gal reporter system was used as an internal control. The miR-431 mimics used in the present study were annealed by the
miR-431 mimic 5'-UAAUUAGUGUCAUGUAGUUAGG-3' and 5'-AGACUACAUGAAGCUACCUAAU-3', and the control group was annealed by 5'-GUCACGGAUCGCGGC ACAUTT-3' and 5'-AAUUGCCACGCGUUGAAGATT-3' (MD Bio, Inc. Gaithersburg, MD, USA). The luciferase activities of the miR-431-transfected HuT-78 and HTL-90 cell lines were quantified and subjected to statistical analyses. Results were normalized against the cells transfected with scrambled miR control.

Statistical analysis. All data were expressed as the mean \pm standard deviation of triplicate dependent experiments and analyzed by using paired Student t-tests or one-way analysis of variance followed by Tukey's post hoc test. All data were analyzed using SPSS Statistics (version 19.0; SPSS, Inc., Chicago, IL, USA) and GraphPad Prism (version 5.0; GraphPad Software, Inc., La Jolla, CA, USA). Microsoft Excel (Microsoft Corporation, Redmond, WA, USA) was also used. * $\mathrm{P}<0.05$ was considered to indicate a statistically significant difference.

\section{Results}

Analysis of Evil and miR-431 expression in AML cells. The expression levels of Evil and miR-431 were analyzed in AML cells. The mRNA and protein expression levels of Evi1 were upregulated in HuT-78 and HTL-90 cells compared with (Fig. 1A and B). The results demonstrated that miR-431 expression levels were significantly downregulated in HuT-78 and HTL-90 compared with normal T lymphocytes (Fig. 1C). The dual-luciferase reporter assay indicated that Evil may 
A

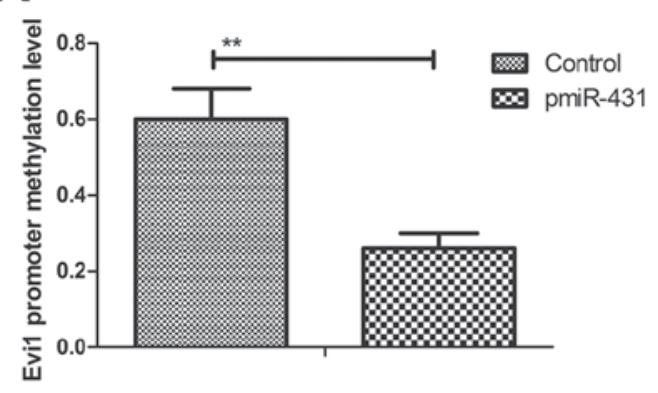

C

Control

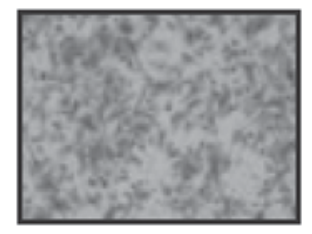

D

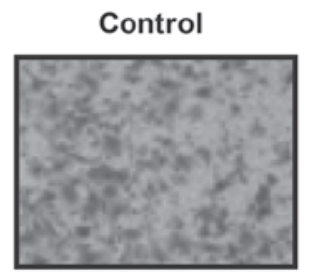

pmiR-431

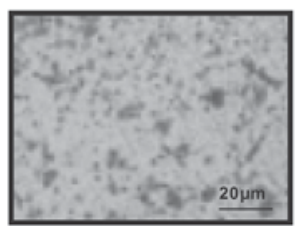

B
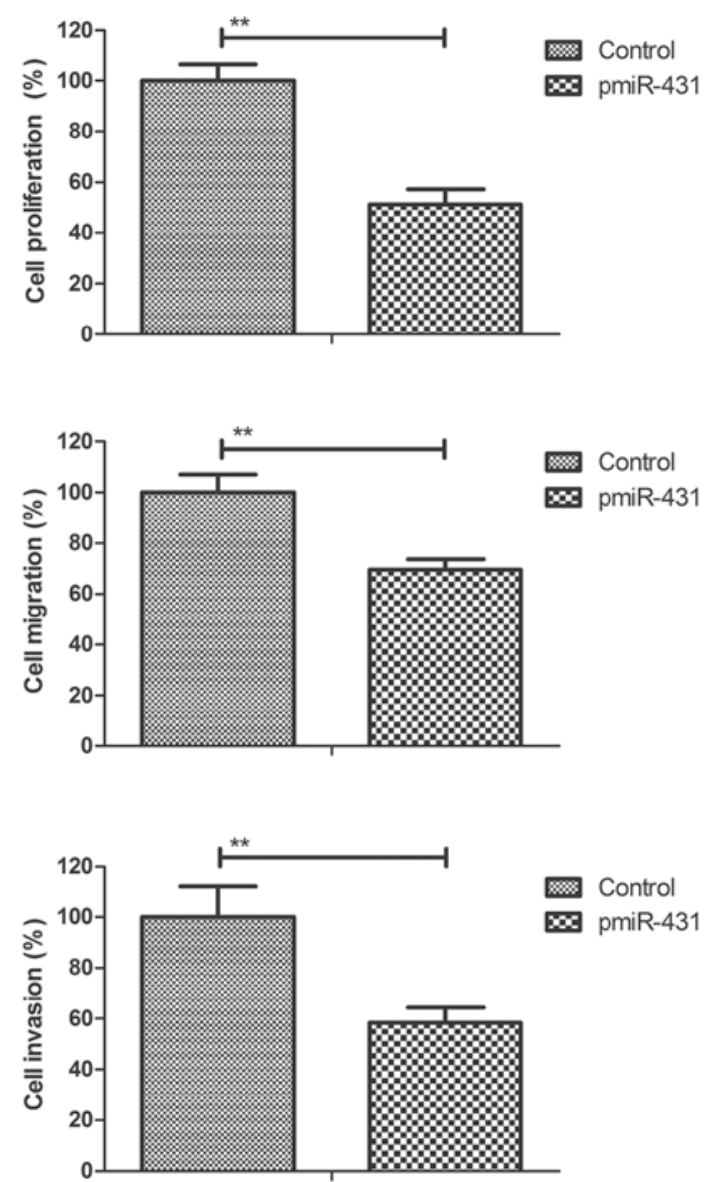

Figure 2. Transfection of miR-431 suppresses the proliferation and invasion of acute myeloid leukemia cells. (A) The transfection of miR-431 mimic decreased the methylation levels of Evil gene promoter in HuT-78 cells. (B) The transfection of miR-431 inhibited the proliferation of HuT-78 cells. The transfection of miR-431 significantly suppressed the (C) migration and (D) invasion of HuT-78 cells. Magnification $\mathrm{x} 40$. ${ }^{* *} \mathrm{P}<0.01$. Evi1, ecotropic viral integration site 1 ; miR, microRNA.

be the target gene of miR-431 in HuT-78 and HTL-90 cells (Fig. 1D). These results suggested that Evi1 may be upregulated and miR-431 expression may be downregulated in HuT-78 and HTL-90 cells.

Transfection of miR-431 inhibits the proliferation and invasion of AML cells. HuT-78 cell line is a typical and is the most representative AML cells (18). Therefore the role of miR-431 in AML cells was analyzed in the present study. In order to investigate the role of miR-431 in HuT-78 cells, the effects of miR-431 on proliferation and invasion were analyzed in HuT-78 cells. The transfection of miR-431 decreased the promoter methylation levels of the Evil gene in HuT-78 cells compared with the control (Fig. 2A). The results revealed that the transfection of miR-431 increased miR-431 expression (data not shown) and inhibited the proliferation of HuT-78 cells compared with the control (Fig. 2B). Furthermore, it was observed that the transfection of miR-431 suppressed the migration and invasion of HuT-78 cells (Fig. 2C and D). These results suggested that the transfection of miR-431 may inhibit the proliferation and invasion of AML cells.

Transfection of miR-431 inhibits MS4A3 and TGF $\beta / E M T$ signaling pathway in AML cells. To identify the potential mechanism mediated by miR-431, the effects of miR-431 on the TGF $\beta /$ EMT signaling pathway in HuT-78 cells were investigated in the present study. As presented in Fig. 3A, the transfection of miR-431 suppressed the expression levels of MS4A3 in HuT-78 cells. It was demonstrated that the transfection of miR-431 decreased the expression levels of TGF $\beta$ and EMT markers (FIB, $\alpha$-SMA and VIM) in HuT-78 cells (Fig. 3B). These results indicated that the transfection of miR-431 may inhibit MS4A3 and TGF $\beta /$ EMT signaling pathways in AML cells.

Overexpression of MS4A3 inhibits miR-431 mediatedinhibition on the expression levels of TGF $\beta$ and EMT markers. To investigate the potential molecular mechanism of miR-431 in the TGF $\beta /$ EMT signaling pathway, the effects of MS4A3 on the expression levels of TGF $\beta$ and EMT markers in HuT-78 cells were analyzed in the present study. It was demonstrated that the overexpression of MS4A3 inhibited the expression levels of TGF $\beta$ and EMT markers in AML cells (Fig. 4A). The transfection of miR-431 mimic suppressed the migration and invasion of AML cells, and this effect was also reversed by MS4A3 overexpression in HuT-78 cells (Fig. 4B and $\mathrm{C}$ ). These results suggested that the overexpression of MS4A3 inhibited miR-431 mediated-inhibition on the expression levels of TGF $\beta$ and EMT markers. 
A

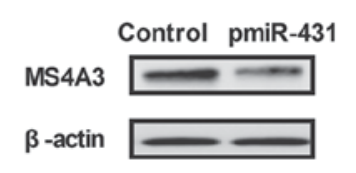

B

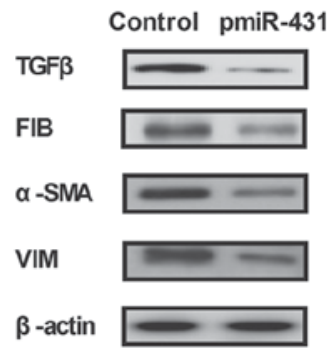

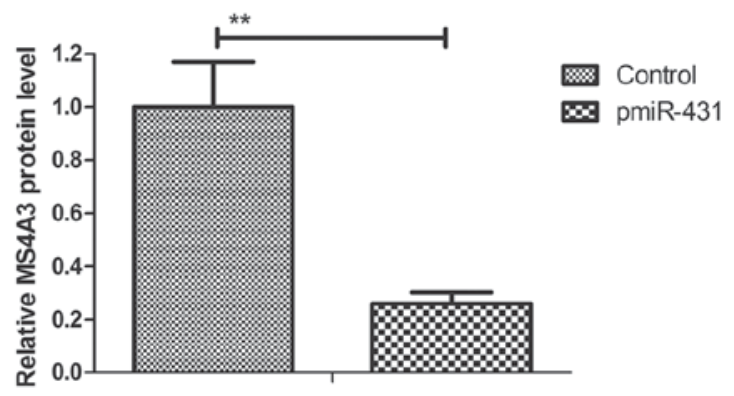

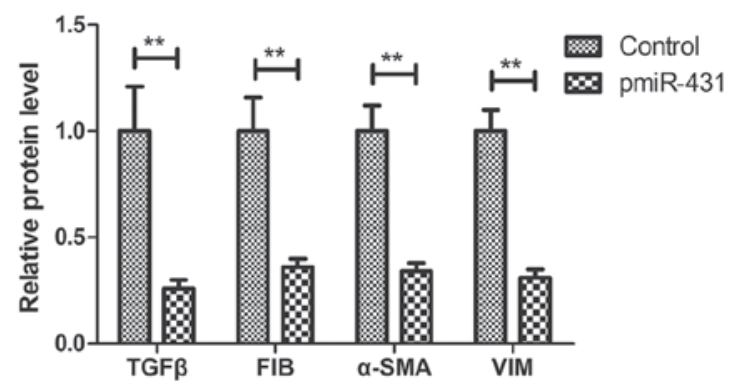

Figure 3. Transfection of miR-431 inhibits MS4A3 and TGF 3 and epithelial-to-mesenchymal transition signaling pathway in acute myeloid leukemia cells. (A) The transfection of miR-431 suppressed MS4A3 expression levels in HuT-78 cells. (B) The transfection of miR-431 decreased the expression levels of TGF $\beta$ and EMT markers in HuT-78 cells. ${ }^{* *} \mathrm{P}<0.01 . \alpha$-SMA, $\alpha$-smooth muscle actin; FIB, fibronectin; miR, microRNA; MS4A3, membrane-spanning-4-domains subfamily-A member-3; transforming growth factor $\beta$; VIM, vimentin.

A
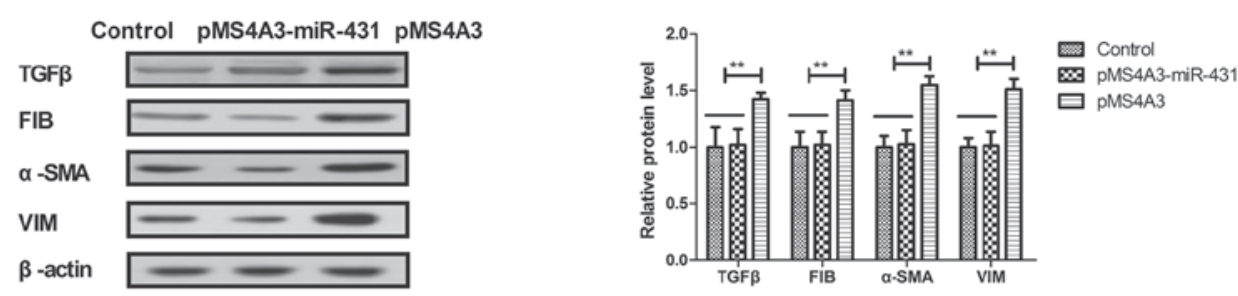

B
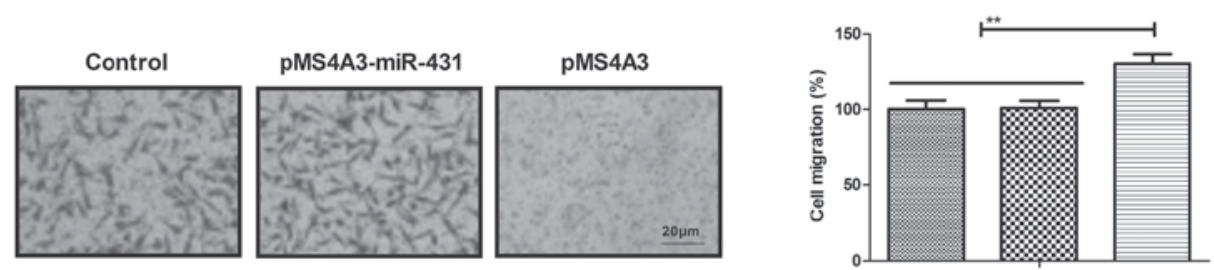

Control

$\bowtie$ pMS4A3-miR-431

$\square$ PMS4A3

C
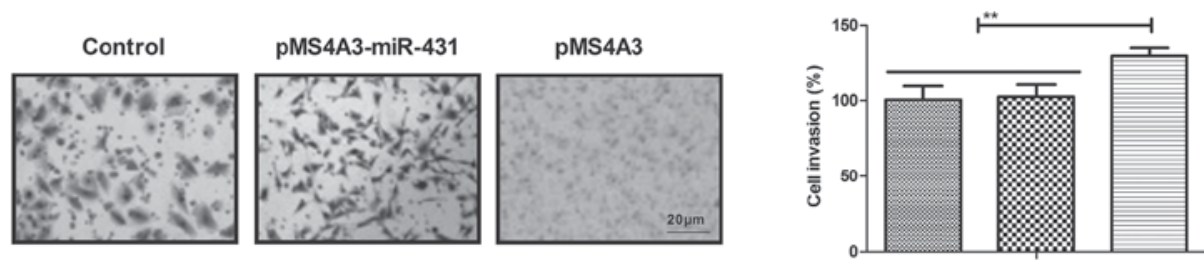

Control

pMS4A3-miR-431

口MS4A3

Figure 4. Overexpression of MS4A3 inhibits miR-431-mediated decrease in TGF $\beta$ and EMT expression levels. (A) The overexpression of MS4A3 repressed the inhibition of TGF $\beta$ and EMT expression that is mediated by miR-431 in AML cells. The transfection of miR-431 suppressed the (B) migration and (C) invasion of AML cells. Magnification $\mathrm{x} 40 .{ }^{* * *} \mathrm{P}<0.01$. AML, acute myeloid leukemia; $\alpha$-SMA, $\alpha$-smooth muscle actin; FIB, fibronectin; miR, microRNA; MS4A3, membrane-spanning-4-domainssubfamily-A member-3; transforming growth factor $\beta$; TGF $\beta$, transforming growth factor $\beta$; VIM, vimentin.

Evil regulates the progression of AML via MS4A3-mediated TGF $/ E M T$ signaling pathway. The TGFß/EMT signaling pathway serves an important role in the progression of AML $(19,20)$. Therefore, the role of Evi1 on MS4A3-mediated 
A
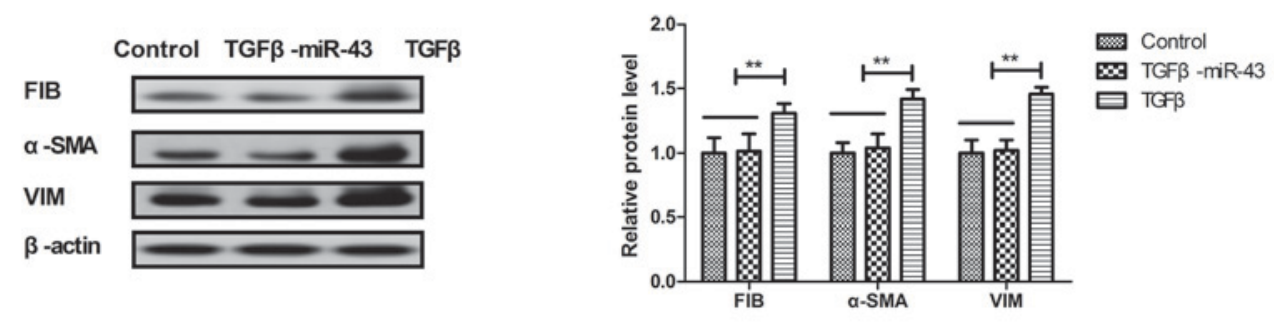

B
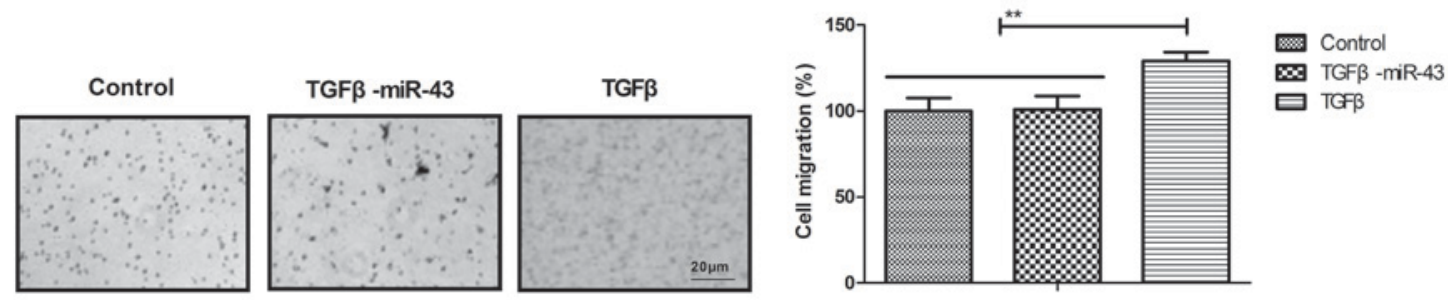

C
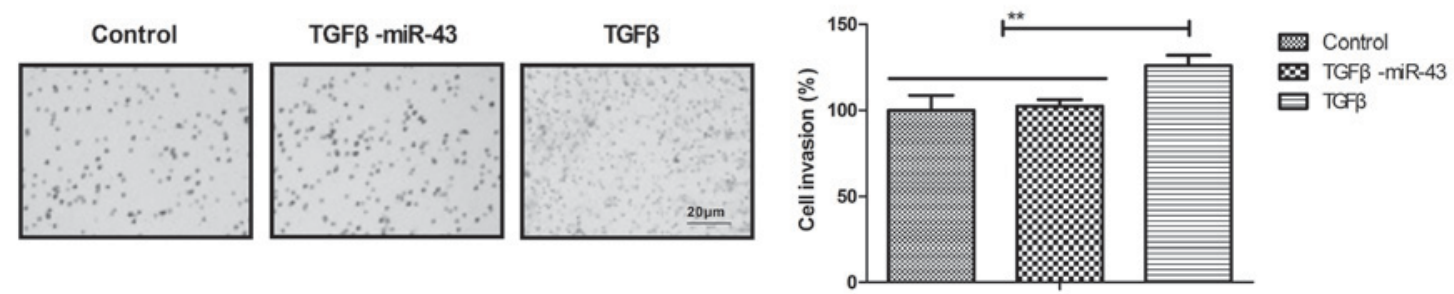

Figure 5. Ecotropic viral integration site 1 regulates the progression of AML via the MS4A3-mediated TGF $\beta /$ EMT signaling pathway. (A) The addition of TGF $\beta$ eliminated the downregulation of EMT markers that is mediated by miR-431 in AML cells. The addition of TGF $\beta$ inhibited MS4A3-induced (B) migration and (C) invasion of AML cells. Magnification $x 40 .{ }^{* * *} \mathrm{P}<0.01$. AML, acute myeloid leukemia; $\alpha$-SMA, $\alpha$-smooth muscle actin; EMT, epithelial-tomesenchymal transition; FIB, fibronectin; miR, microRNA; MS4A3, membrane-spanning-4-domains subfamily-A member-3; TGF $\beta$, transforming growth factor $\beta$; VIM, vimentin.

TGF $\beta /$ EMT signaling pathway in HuT-78 cells was analyzed in the present study. It was demonstrated that the addition of TGF $\beta$ eliminated the downregulation of EMT markers that is mediated by miR-431 mimics in AML cells (Fig. 5A). The addition of TGF $\beta$ promoted the migration and invasion of AML cells compared with the control and reversed the inhibition on migration and invasion of AML cells that is mediated by miR-431 mimic (Fig. 5B and C). These results suggested that Evi1 may regulate the progression of AML via MS4A3-mediated TGF $\beta /$ EMT signaling.

\section{Discussion}

The overexpression of the Evil oncogene gene is associated with typically aggressive myeloid leukemia $(21,22)$. In the present study, a putative target of Evil in the progression of AML was analyzed. A previous study reported that Evi1 overexpression was predominantly detected within subtypes of pediatric AML in distinct subtypes of pediatric AML (23). The results of the present study indicated that Evil was upregulated and miR-431 expression was downregulated in HuT-78 and HTL-90 cells compared with normal T lymphocytes. The findings also indicated that the transfection of miR-431 inhibited the proliferation and invasion of AML cells, which further suppressed the MS4A3/TGF $\beta /$ EMT signaling pathway in
AML cells. Notably, the results of the present study indicated that Evi1 may regulate the proliferation and invasion of AML via MS4A3-mediated TGF $3 /$ EMT signaling.

The Evil gene may serve as an alternative minimal residual disease marker in AML on the basis of increasing expression levels of MDS1-EVI/EVI 29, 36 and 93 days prior to hematologic manifestation, particularly in samples where other specific markers are lacking (24). Previous studies have reported that high expression of Evil may predict the outcome of younger adult patients ( $<22$ years old) with AML, which was associated with distinct cytogenetic abnormalities $(23,25)$. In the present study, it was observed that the inhibition of Evil expression mediated by miR-431 transfection significantly inhibited the proliferation and invasion of AML cells. A previous study reported that EVI1 may bind to and downregulate Serpin family B member 2, which is involved in the Janus kinase-signal transducers and activators of transcription signaling pathway, suggesting that Evil is a target gene in the treatment of AML (26). The results of the present study reported that miR-431 may regulate MS4A3-mediated TGF $\beta$ and EMT signaling pathway in AML cells.

MS4A3 is a member of a family of four-transmembrane proteins, which acts as a cell surface signaling molecule and an intracellular adapter protein (27). Heller et al (12) indicated that Evi1 may promote tumor growth via transcriptional 
repression of MS4A3. The results of the present study confirmed previous results and reported that Evil regulated MS4A3 via regulation of miR-431 levels. Pan et al (28) analyzed the association between the downregulation of miR-431 expression and clinicopathological characteristics in hepatocellular carcinoma tissues. In the present study, the results revealed that miR-431 transfection inhibited the invasion of AML cells, which was abolished by the overexpression of MS4A3.

The TGF $\beta / E M T$ signaling pathway serves a crucial role in mediating tumor suppressive effects in human cutaneous melanoma (20). TGF $\beta$-mediated formation of retinoblastoma protein-E2F complexes has been demonstrated to be involved in the proliferation and invasion of human myeloid leukemia cells (29). The results of the present study indicated that the overexpression of MS4A3 inhibited the expression TGF $\beta$ and EMT markers, which is mediated by miR-431 mimic in AML cells. Additionally, the transfection of miR-431 mimic suppressed the migration and invasion of AML cells, and this effect was also reversed by MS4A3 overexpression in HuT-78 cells. Notably, the addition of TGF $\beta$ abolished the downregulation of EMT markers, which is mediated by transfection of miR-431 mimic. This finding suggests that Evil may regulate the progression of AML via the miR-431/EVI1/MS4A3-mediated TGF $3 /$ EMT signaling pathway.

In conclusion, the silencing of Evil by miR-431 transfection exerted inhibitory effects on MS4A3-mediated TGF $\beta /$ EMT signaling pathway in AML cells. The findings of the present study demonstrated that the oncogenic agent miR-431 may contribute to the inhibition of Evi1-positive AML cells. In addition, the present study revealed that the targeting of Evi1 by miR-431 transfection reversed the downregulation of EMT markers (FIB, $\alpha$-SMA and VIM) in HuT-78 cells, which attenuated the proliferation and invasion of AML cells. These findings suggested that Evil may be a novel therapeutic agent for the treatment of AML.

\section{Acknowledgements}

Not applicable.

\section{Funding}

The present study was supported by the Xiamen Science and Technology Plan Project (grant no. 3502Z20164066) and The Fujian Province medical innovation project (grant no. 2017-CXB-19). National Natural Science Foundation of China (grant no. 61427807) and National Key R\&D Program of China (grant no. 2017YFC1103403).

\section{Availability of data and materials}

The datasets used and/or analyzed during the current study are available from the corresponding author on reasonable request.

\section{Authors' contributions}

MJ performed the experiments and wrote the paper. XZ contributes to the data analysis and $\mathrm{WH}$ is the designer for this study.

\section{Ethics approval and consent to participate}

Not applicable.

\section{Consent for publication}

No applicable.

\section{Competing interests}

The authors declare that they have no competing interests.

\section{References}

1. Varkaris A, Gunturu K, Kewalramani T and Tretter C: Acute myeloid leukemia after radium-223 therapy: Case report. Clin Genitourin Cancer 15: e723-726, 2016.

2. Huang L, Wang SA, DiNardo C, Li S, Hu S, Xu J, Zhou W, Goswami M, Medeiros LJ and Tang G: Tetraploidy/neartetraploidy acute myeloid leukemia. Leuk Res 53: 20-27, 2017.

3. Yamaguchi H: Gene mutations in acute myeloid leukemia. Rinsho Ketsueki 57: 2535-2542, 2016 (In Japanese).

4. Uchida T, Hagihara M, Hua J and Inoue M: The effects of azacitidine on the response and prognosis of myelodysplastic syndrome and acute myeloid leukemia involving a bone marrow erythroblast frequency of $>50$. Leuk Res 53: 35-38, 2017.

5. Zhao SY, Tuerxun N, Chen R and Hao JP: Analysis of therapy and efficacy after remission of acute myeloid leukemia. Zhongguo Shi Yan Xue Ye Xue Za Zhi 24: 1721-1724, 2016 (In Chinese).

6. Liu C, Zhao L, Zhao J, Xu Q, Song Y and Wang H: Reduced ADAMTS-13 level negatively correlates with inflammation factors in plasma of acute myeloid leukemia patients. Leuk Res 53: 57-64, 2017.

7. Montewis A and Eveillard M: Acute myeloid leukemia with erythrophagocytosis indicative of KAT6A rearrangement. Blood 128: 314, 2016.

8. Pradhan AK, Halder A and Chakraborty S: Physical and functional interaction of the proto-oncogene EVI1 and tumor suppressor gene $\mathrm{HIC} 1$ deregulates $\mathrm{Bcl}-\mathrm{xL}$ mediated block in apoptosis. Int J Biochem Cell Biol 53: 320-328, 2014.

9. Louz D, van den Broek M, Verbakel S, Vankan Y, van Lom K, Joosten M, Meijer D, Löwenberg B and Delwel R: Erythroid defects and increased retrovirally-induced tumor formation in Evi1 transgenic mice. Leukemia 14: 1876-1884, 2000.

10. Nanjundan M, Nakayama Y, Cheng KW, Lahad J, Liu J, Lu K, Kuo WL, Smith-McCune K, Fishman D, Gray JW and Mills GB: Amplification of MDS1/EVI1 and EVI1, located in the 3q26.2 amplicon, is associated with favorable patient prognosis in ovarian cancer. Cancer Res 67: 3074-3084, 2007.

11. Jazaeri AA, Ferriss JS, Bryant JL, Dalton MS and Dutta A: Evaluation of EVI1 and EVI1s (Delta324) as potential therapeutic targets in ovarian cancer. Gynecol Oncol 118: 189-195, 2010.

12. Heller G, Rommer A, Steinleitner K, Etzler J, Hackl H, Heffeter P, Tomasich E, Filipits M, Steinmetz B, Topakian T, et al: EVI1 promotes tumor growth via transcriptional repression of MS4A3. J Hematol Oncol 8: 28, 2015.

13. Gao JS,Zhang Y, Tang X, TuckerLD, Tarwater PM, Quesenberry PJ, Rigoutsos I and Ramratnam B: The Evil, microRNA-143, K-Ras axis in colon cancer. FEBS Lett 585: 693-699, 2011.

14. Nayak KB, Kuila N, Das Mohapatra A, Panda AK and Chakraborty S: EVI1 targets $\Delta \mathrm{Np} 63$ and upregulates the cyclin dependent kinase inhibitor p21 independent of p53 to delay cell cycle progression and cell proliferation in colon cancer cells. Int J Biochem Cell Biol 45: 1568-1576, 2013.

15. Zhang M, Xiao X, Liang Y, Peng M, Jiang Y, Xu Y and Gong G: Effect of methylation inhibitor on demethylation pattern of the PD-1 gene in promoter region and PD-1 expression in human T lymphocyte cell line. Zhong Nan Da Xue Xue Bao. Yi Xue Ban 36: 1163-1169, 2011 (In Chinese).

16. Livak KJ and Schmittgen TD: Analysis of relative gene expression data using real-time quantitative PCR and the 2(-delta delta C(T)) method. Methods 25: 402-408, 2001.

17. Banerjee S, Yang S and Foster CB: A luciferase reporter assay to investigate the differential selenium-dependent stability of selenoprotein mRNAs. J Nutr Biochem 23: 1294-1301, 2012. 
18. Pham MH, Kondapalli N, Reckord CL and Foglesong PD: Interleukin-2 induces the activities of DNA topoisomerase I and DNA topoisomerase II in HuT 78 cells. Biochem Biophys Res Commun 390: 577-580, 2009.

19. Yue X, Zhao Y, Zhang C, Li J, Liu Z, Liu J and Hu W: Leukemia inhibitory factor promotes EMT through STAT3-dependent miR-21 induction. Oncotarget 7: 3777-3790, 2016.

20. Humbert L, Ghozlan M, Canaff L, Tian J and Lebrun JJ: The leukemia inhibitory factor (LIF) and p21 mediate the TGF $\beta$ tumor suppressive effects in human cutaneous melanoma. BMC Cancer 15: 200, 2015.

21. Noordermeer SM, Monteferrario D, Sanders MA, Bullinger L, Jansen JH and van der Reijden BA: Improved classification of MLL-AF9-positive acute myeloid leukemia patients based on BRE and EVI1 expression. Blood 119: 4335-4337, 2012

22. Vázquez I, Maicas M, Cervera J, Agirre X, Marin-Béjar O, Marcotegui N, Vicente C, Lahortiga I, Gomez-Benito M, Carranza C, et al: Down-regulation of EVI1 is associated with epigenetic alterations and good prognosis in patients with acute myeloid leukemia. Haematologica 96: 1448-1456, 2011.

23. Balgobind BV, Lugthart S, Hollink IH, Arentsen-Peters ST, van Wering ER, de Graaf SS, Reinhardt D, Creutzig U, Kaspers GJ, de Bont ES, et al: EVI1 overexpression in distinct subtypes of pediatric acute myeloid leukemia. Leukemia 24: 942-949, 2010.
24. Weisser M, Haferlach C, Haferlach T and Schnittger S: Feasibility of using the combined MDS-EVI1/EVI1 gene expression as an alternative molecular marker in acute myeloid leukemia: A report of four cases. Cancer Genet Cytogenet 177: 64-69, 2007.

25. Gröschel S, Lugthart S, Schlenk RF, Valk PJ, Eiwen K, Goudswaard C, van Putten WJ, Kayser S, Verdonck LF, Lübbert M, et al: High EVI1 expression predicts outcome in younger adult patients with acute myeloid leukemia and is associated with distinct cytogenetic abnormalities. J Clin Oncol 28: 2101-2107, 2010.

26. Glass C, Wuertzer C, Cui X, Bi Y, Davuluri R, Xiao YY, Wilson M, Owens K, Zhang Y and Perkins A: Global identification of EVI1 target genes in acute myeloid leukemia. PloS One 8: e67134, 2013.

27. Kutok JL, Yang X, Folkerth R and Adra CN: Characterization of the expression of HTm4 (MS4A3), a cell cycle regulator, in human peripheral blood cells and normal and malignant tissues. J Cell Mol Med 15: 86-93, 2011.

28. Pan L, Ren F, Rong M, Dang Y, Luo Y, Luo D and Chen G: Correlation between down-expression of miR-431 and clinicopathological significance in HCC tissues. Clin Transl Oncol 17: 557-563, 2015.

29. Hu XT: TGFbeta-mediated formation of pRb-E2F complexes in human myeloid leukemia cells. Biochem Biophys Res Commun 369: 277-280, 2008. 